\title{
Childhood Sexual Abuse: Scars Left for Life
}

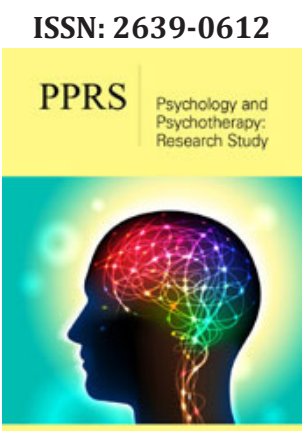

*Corresponding author: Department of Clinical Psychology, Central Institute of Psychiatry, India

Submission: 価 March 10, 2020

Published: 眥June 29, 2020

Volume 3 - Issue 5

How to cite this article: Alisha Arora. Childhood Sexual Abuse: Scars Left for Life. Psychol Psychother Res Stud. 3(5). PPRS. 000574. 2020.

DOI: 10.31031/PPRS.2020.03.000574

Copyright@ Alisha Arora, This article is distributed under the terms of the Creative Commons Attribution 4.0 International License, which permits unrestricted use and redistribution provided that the original author and source are credited.

\author{
Alisha Arora* \\ Department of Clinical Psychology, India
}

\begin{abstract}
The occurrence and prevalence of childhood sexual abuse (CSA) is a growing concern across the globe. The survivors of CSA experience its aftermath for years. The post-trauma consequences were classified broadly as-(i) physical, (ii) psychiatric, and (iii) psychosocial. The present review highlights the extant association of CSA with outcomes ranging from somatic/physical pain to psychiatric disorders to psychosocial dynamics of school dropout, sexual re-victimization, and sexual offending. The scars of CSA are deep rooted and through the review the need was observed to address the problem with extensive programs, interventions and policies, at the earliest stages.
\end{abstract}

Keywords: Childhood sexual abuse; Trauma; Outcomes; Trauma survivors

\section{Childhood Sexual Abuse: Scars Left for Life}

Childhood Sexual Abuse (CSA) is a global concern which is increasing in prevalence worldwide. The World Health Organization [1] defines CSA as "the involvement of a child in sexual activity that he or she does not fully comprehend and is unable to give informed consent to, or for which the child is not developmentally prepared, or else that violate the laws or social taboos of society". Prevalence rates of CSA are concerning with females being more targeted. In a recent review by Barth et al. [2], it was observed that CSA prevalence rates were 8 to $31 \%$ for girls and 3 to $17 \%$ for boys. There has been a widespread work on the clinical outcomes and consequences of CSA, depicting the chronic scars it leaves behind. The consequences can broadly be categorized as physical, psychiatric, and psychosocial. CSA survivors are exposed to a varied range of impairment and difficulties in their adulthood and are always more vulnerable than their counterparts. Physical outcomes mostly include gastrointestinal symptoms, obesity, fibromyalgia, fatigue, irritable bowel syndrome, and asthma [3]. Estimates of a history of CSA among a population of women diagnosed with fibromyalgia range from 50 to $67 \%$ [4]. Among the ones suffering from non-organic gastrointestinal health issues, CSA survivors account for $53 \%$ [5].

Chronic hyper-arousal of the stress response and hyper-vigilance to the environment as a consequence of CSA makes survivors more vulnerable to stress. Stress, in turn leads to complex disease processes. Hence, among survivors, a reduced immune capacity and resultant health consequences are seen for a long time. CSA exposure considerably impacts the metabolic processes, as a result of increase in stress hormone. obesity is common among most of the survivors. Depression, a mental health outcome further reinforces obesity. Psychiatric manifestations depict the severity of mental health outcome. Post-Traumatic Stress Disorder (PTSD) is a commonly associated consequence [6] which can be an etiological cause for coping skill deficits and poor problem-solving skills among survivors. Deficits in these life skills pave the way for depression, anxiety, and maladaptive personalities [7]. Along with biochemical factors, psychological mechanisms involving cognitive errors and poor coping skills are primary reasons of mood disorders among survivors. Beliefs such as I am not lovable,, 'People are bad', 'I cannot deal myself' are errors which persists post-event. Eating disorders are also associated with CSA primarily involving bulimia nervosa and binge eating pattern [8]. Eating and purging can be faulty coping mechanism for stress in victims. Substance abuse, after PTSD is the most commonly studied outcome among CSA survivors [9].

According to Devries et al. [10], CSA is associated with increased odds of suicide attempts. Klonsky and Moyer [11] explain that self-injurious behaviour is a proxy consequence of oth- 
er psychiatric vulnerabilities which occur as a CSA consequence. Dissociation, alexithymia, and borderline personality disorder has relatively higher link with CSA aftermath and act as moderators for suicidal behaviour/tendency. Psychosocial dynamics are perhaps the most extensive and deep scars CSA leads to. Lloyd et al. [12] explains sexual re-victimization, risky sex behaviour and risk of sexually transmitted diseases (like HIV) prominent among CSA survivors. Poor frustration tolerance and dissatisfaction may validate findings that CSA survivors have poor quality of relationships with partners [13]. Duncan [14] found in his longitudinal study that exposure to CSA leads to school/college dropout (up to 65\%) and low scholastic performance. The effects of CSA at the family level may be economic, resulting in loss of income that may lead to change of residency and dropping out of school for the survivor [15]. In addition, sexual offending by survivors, involving offense against adults and/ or children has also been indicated [16]. The sexually abused-sexual abuser association can be explained on basis of learning theory as per Burton [17] who mentions it as imitation of the perpetrator's behavior and reinforcement of associated attitudes, and beliefs.

India is home to a vast youth population. Exposure to trauma, specifically CSA remains a challenge. Less reporting of cases and associated stigma further bleaks the chance of reaching out to victims. The effects are either immediate or long term and lack of help ends most of them in hospitals or jails. Interventions and regulations have led to development of stricter laws. But the destination is still far away. Effects of CSA are varied and not uniform. It affects the victim, their families and their future, for a longer duration. Physical, psychiatric, and psychosocial outcomes have been evidenced in studies across globe. However, non-uniform definition of CSA, non-experimental methodology and reduced report rates of CSA weakens the empirical value. But we cannot ignore the fact that outcomes are there, and they are life changing. The essential message is to extensively work upon the programs, interventions and policies may ensure minimizing the exposure of CSA and provide the children and society, a safer-healthier future.

\section{References}

1. World Health Organization (2003) Child sexual abuse: Guidelines for medico legal care for victims of sexual violence. World Health organization: Child Sexual abuse.

2. Barth J, Bermetz L, Heim E, Trelle S, Toni T (2013) The current prevalence of child sexual abuse worldwide: A systematic review and meta-analysis. Int J Public Health 58: 469-483.
3. Danese A, Tan M (2014) Childhood maltreatment and obesity: Systematic review and meta-analysis. Mol Psychiatry 19(5): 544-554.

4. Wilson DR (2009) Stress management for adult survivors of childhood sexual abuse: A holistic inquiry. Western Journal of Nursing Research 32(1): 103-127.

5. Hulme PA (2000) Symptomatology and health care utilization of women primary care patients who experienced childhood sexual abuse. Child Abuse Negl 24(11): 1471-1484.

6. Chen LP, Murad MH, Paras ML, Colbenson KM, Sattler AL, et al. (2010) Sexual abuse and lifetime diagnosis of psychiatric disorders: Systematic review and meta-analysis. Mayo Clin Proc 85(7): 618-629.

7. Amado BG, Arce R, Herraiz A (2015) Psychological injury in victims of child sexual abuse: A meta-analytic review. Psychosocial Intervention 24(1): 49-62.

8. Molendijk ML, Hoek HW, Brewerton TD, Elzinga BM (2017) Childhood maltreatment and eating disorder pathology: A systematic review and dose-response meta-analysis. Psychol Med 47(8): 1402-1416.

9. Halpern SC, Felipe BS, Juliana NS, Anne OS, Mayra P, et al. (2018) Child maltreatment and illicit substance abuse: A Systematic review and Metaanalysis of longitudinal studies. Child Abuse Review 27(5): 344-360.

10. Devries KM, Mak JY, Child JC, Falder G, Bacchus LJ, et al. (2014) Childhood sexual abuse and suicidal behavior: A Meta-analysis. Pediatrics 133(5): e1331-e1344.

11. Klonsky ED, Moyer A (2008) Childhood sexual abuse and non-suicidal self-injury: Meta-analysis. Br J Psychiatry 192(3): 166-170.

12. Lloyd S, Operario D (2012) HIV risk among men who have sex with men who have experienced childhood sexual abuse: systematic review and meta-analysis. AIDS Educ Prev 24(3): 228-241.

13. Dennerstein L, Guthrie JR, Alford S (2004) Childhood abuse and its association with mid-aged women's sexual functioning. J Sex Marital Ther 30(4): 225-234.

14. Duncan RD (2000) Childhood maltreatment and college drop-out rates: Implications for child abuse researchers. Journal of Interpersonal Violence 15(9): 987-996.

15. Tavkar P, Hansen DJ (2011) Interventions for families victimized by child sexual abuse: Clinical issues and approaches for child advocacy center-based services. Aggression and Violent Behavior 16(3): 188-199.

16. Jespersen AF, Lalumière ML, Seto MC (2009) Sexual abuse history among adult sex offenders and non-sex offenders: A meta-analysis. Child Abuse \& Neglect 33(3): 179-192.

17. Burton DL (2003) Male adolescents: Sexual victimization and subsequent sexual abuse. Child and Adolescent Social Work Journal 20(4): 277-296. 